\title{
Dietary patterns, insulin sensitivity and adiposity in the multi-ethnic Insulin Resistance Atherosclerosis Study population
}

\author{
Angela D. Liese ${ }^{1 *}$, Mandy Schulz ${ }^{1,2}$, Charity G. Moore ${ }^{1}$ and Elizabeth J. Mayer-Davis ${ }^{1,3}$ \\ ${ }^{1}$ Department of Epidemiology and Biostatistics, Arnold School of Public Health, University of South Carolina, \\ 800 Sumter street, Columbia, South Carolina 29208, USA \\ ${ }^{2}$ German Institute of Human Nutrition, Department of Epidemiology, Potsdam-Rehbruecke, Germany \\ ${ }^{3}$ Center for Research in Nutrition and Health Disparities, Arnold School of Public Health, University of South Carolina, \\ Columbia, South Carolina, USA
}

(Received 12 April 2004 - Revised 9 August 2004 - Accepted 16 August 2004)

\begin{abstract}
Epidemiological investigations increasingly employ dietary-pattern techniques to fully integrate dietary data. The present study evaluated the relationship of dietary patterns identified by cluster analysis with measures of insulin sensitivity $\left(\mathrm{S}_{\mathrm{I}}\right)$ and adiposity in the multi-ethnic, multi-centre Insulin Resistance Atherosclerosis Study (IRAS, 1992-94). Cross-sectional data from 980 middle-aged adults, of whom $67 \%$ had normal and $33 \%$ had impaired glucose tolerance, were analysed. Usual dietary intake was obtained by an interviewer-administered, validated food-frequency questionnaire. Outcomes included $\mathrm{S}_{\mathrm{I}}$, fasting insulin (FI), BMI and waist circumference. The relationship of dietary patterns to $\log \left(\mathrm{S}_{\mathrm{I}}+1\right), \log (\mathrm{FI}), \mathrm{BMI}$ and waist circumference was modelled with multivariable linear regressions. Cluster analysis identified six distinct diet patterns - 'dark bread', 'wine', 'fruits', 'low-frequency eaters', 'fries' and 'white bread'. The 'white bread' and the 'fries' patterns over-represented the Hispanic IRAS population predominantly from two centres, while the 'wine' and 'dark bread' groups were dominated by non-Hispanic whites. The dietary patterns were associated significantly with each of the outcomes first at the crude, clinical level $(P<0 \cdot 001)$. Furthermore, they were significantly associated with FI, BMI and waist circumference independent of age, sex, race or ethnicity, clinic, family history of diabetes, smoking and activity $(P<0 \cdot 004)$, whereas significance was lost for $\mathrm{S}_{\mathrm{I}}$. Studying the total dietary behaviour via a pattern approach allowed us to focus both on the qualitative and quantitative dimensions of diet. The present study identified highly consistent associations of distinct dietary patterns with measures of insulin resistance and adiposity, which are risk factors for diabetes and heart disease.
\end{abstract}

Diet: Epidemiological studies: Insulin resistance: Nutrition

To examine the effects of overall diet on health outcomes, epidemiological investigations are increasingly adding dietary-pattern approaches to the more traditional focus on individual foods, nutrients or dietary constituents. Given the high degree of co-linearity in the intake of individual foods and nutrients, multivariate approaches have been fraught with questions related to the appropriateness of confounder control and the interactions between foods or between nutrients. Dietary-pattern analysis may prove an informative addition in that it more fully captures the effect of total dietary behaviour in disease aetiology (Jacobs \& Steffen, 2003).

Two multivariate techniques have dominated analyses of dietary patterns, namely cluster and factor analysis. Factor analysis reduces information from many foods into a small number of uncorrelated factor scores by utilising the covariance structure among the foods (Morrison, 1990). Each individual is then assigned a score for each of the factors identified. In aetiological studies, the dietary-pattern score is subsequently related to a health outcome either by correlation or after categorisation. Cluster analysis groups individuals with similar dietary characteristics based on Euclidean distance measures (Romesburg, 1984). The procedure aims to minimise the differences on the entire array of foods within each group of individuals while maximising the difference between groups. These groups of individuals can be easily studied with regard to traditional epidemiological characteristics such as age, sex, race or ethnicity, or behavioural characteristics and with regard to health outcomes. The appeal of both these methods lies in their ability to identify dietary patterns integrating the full dietary information collected, i.e. considering the entire spectrum of foods ascertained simultaneously and thus reflecting the totality of the food intake.

Previous work has suggested that dietary patterns defined by either cluster or factor analysis are associated with various diseases or disease risk factors with strong nutritional aetiologies. While the data on diabetes and 
CHD (Hu et al. 2000; van Dam et al. 2002) have been quite consistent, evidence for a relationship of dietary patterns with BMI is controversial (Togo et al. 2001). Very little is known about the association of dietary patterns with markers of insulin resistance or the metabolic syndrome (Fung et al. 2001; Wirfält et al. 2001). In the present study, we explored the relationship of behaviour patterns such as food intake with markers of physiological processes of insulin resistance and adiposity that may lead to the metabolic syndrome, diabetes or CHD. Because we were interested in more closely characterising groups of people, we identified distinct dietary behaviour patterns using cluster analysis and subsequently evaluated differences in metabolic and anthropometric characteristics influenced by these dietary behaviours, such as insulin sensitivity $\left(\mathrm{S}_{\mathrm{I}}\right)$, fasting insulin $(\mathrm{FI})$, BMI and waist circumference.

\section{Materials and methods}

\section{Population}

The design of the Insulin Resistance Atherosclerosis Study (IRAS) has been described in detail elsewhere (Wagenknecht et al. 1995). More than 1600 participants were recruited at four clinical centres between 1992 and 1994 for the IRAS baseline examination. The goal was to obtain nearly equal representation of participants across glucose tolerance status (normal, impaired glucose tolerance and non-insulin-taking type 2 diabetes mellitus), race and ethnicity (African-American, Hispanic and nonHispanic white), sex and age (40-49 years, 50-59 years and 60-69 years). Race and ethnicity was determined by self-report using 1990 US census questions. Two of the clinical centres (Los Angeles, CA and Oakland, CA) recruited African-American and non-Hispanic white participants. The other two clinical centres (San Luis Valley, $\mathrm{CO}$ and San Antonio, TX) recruited Hispanic and non-Hispanic white participants. The final sample comprised 1625 individuals, of whom $38 \%$ were non-Hispanic white, $34 \%$ Hispanic and $29 \%$ African-American. Normal glucose tolerance was present in $44.4 \%, 22.7 \%$ had impaired glucose tolerance and $33.1 \%$ had type 2 diabetes. All participants provided written informed consent as approved by their respective field centre's institutional review board.

\section{Data collection}

The IRAS required a two-visit protocol, the first to determine glucose tolerance status and the second to measure $S_{\mathrm{I}}$. Participants were asked to fast for $12 \mathrm{~h}$ before each of the two visits, abstain from heavy exercise and alcohol for $24 \mathrm{~h}$ and refrain from smoking on the morning of the visit. A $2 \mathrm{~h}$, $75 \mathrm{~g}$ oral glucose tolerance test (Orange-dex; Custom Laboratories, Baltimore, MD, USA) was performed during the first visit and WHO criteria (World Health Organization, 1985) were used to assign glucose tolerance status. Individuals currently taking oral hypoglycaemic medications were classified as having type 2 diabetes regardless of the results of the oral glucose tolerance test. $\mathrm{S}_{\mathrm{I}}$ was assessed using the frequently sampled intravenous glucose tolerance test (Bergman et al. 1985; Yang et al. 1987) with minimal model analysis (Pacini \& Bergman, 1986). Details have been described previously (Saad et al. 1994; Wagenknecht et al. 1995). Fasting plasma insulin was determined by radioimmunoassay (Herbert et al. 1965).

Anthropometric measures were taken with the participant in lightweight clothing with shoes removed. Height and weight were measured in duplicate and recorded to the nearest $0.5 \mathrm{~cm}$ and $0.1 \mathrm{~kg}$, respectively. BMI was calculated as weight $/ \mathrm{height}^{2}\left(\mathrm{~kg} / \mathrm{m}^{2}\right)$. Minimum waist circumference was measured using a flexible steel tape measure at the natural indentation or at a level midway between the iliac crest and the lower edge of the ribcage if no natural indentation was visible. Waist circumference was recorded to the nearest $0.5 \mathrm{~cm}$, and the mean of two measures within $1 \mathrm{~cm}$ of each other was used. Usual frequency of vigorous physical activity was ascertained in an interviewer-administered, 1-year activity recall that incorporated activities current among IRAS participants (Mayer-Davis et al. 1998). This scale has been shown to be predictive of incident type 2 diabetes mellitus in the Health Professionals' Study (Manson et al. 1992).

Usual intake of foods and nutrients was assessed by interview using a 1-year, semi-quantitative 114-item food-frequency questionnaire interview modified from the National Cancer Institute Health History and Habits Questionnaire to include regional and ethnic food choices across the four clinical centres. This instrument has been validated in a subset of the IRAS population (Mayer-Davis et al. 1999), demonstrating comparable validity and reproducibility for the African-American, Hispanic and non-Hispanic white populations. Participants were asked to recall their usual intake of foods and beverages over the past 1 year. Both the frequency of intake and the serving size were ascertained. For analyses, the servings per d were standardised to the medium serving size by multiplying the intake frequency with the serving size after applying a weighting factor $($ small $=0.5$; medium $=1.0$; large $=1.5)$. We furthermore collapsed the 114 line items of the food-frequency questionnaire into thirty-three food groups (see Appendix) based on similarities in food and nutrient composition and computed number of daily intake servings for each of those groups. Participants were also queried as to special diets they currently followed, use of dietary supplements and food preparation methods. Interviewers were centrally trained and certified, and audiotapes of interviews were reviewed quarterly. The nutrient database (HHHQ-DIETSYS analysis software, version 3.0; NCI, Bethesda, MD, USA, 1993) was expanded to new foods and to include several additional nutrients. Alcohol intake was evaluated separately using a frequency approach with additional questions about recent use and average lifetime use.

\section{Statistical analysis}

We limited our cross-sectional analyses to 1087 individuals with normal $(67 \%)$ or impaired $(33 \%)$ glucose tolerance, the latter category being over-represented. We excluded individuals with previously or recently diagnosed diabetes at baseline because this might have altered their dietary behaviour. We subsequently excluded eighty-four participants due to missing data on $\mathrm{S}_{\mathrm{I}}$, two with missing 
FI data and four with missing anthropometric data. Due to missing values in covariates, another seventeen subjects were excluded from the analysis. This left 980 participants with complete data for analysis.

In preparation for the dietary-pattern analysis, the number of servings consumed per $\mathrm{d}$ for each of the thirty-three food groups was standardised by converting to the standard normal deviate (mean $=0$; standard deviation $=1$ ) of each food group, respectively. This procedure removes any unequal contribution of variables due to higher variability, avoiding food groups with larger ranges of values having more influence on the generation of clusters than variables with a smaller range of values (Romesburg, 1984). Cluster analysis was employed to identify dietary patterns. We generated dietary-pattern groups using the FASTCLUS procedure in SAS version 8.2 (SAS Institute Inc., Cary, NC, USA). The procedure groups individuals into a predetermined number of mutually exclusive clusters based on minimising Euclidean distances within clusters and maximising these distances across clusters. These distances are calculated based on the differences between an individual's vector of observed values and each cluster centroid, which is a vector of means for the variables included in the cluster analysis. To identify the optimal number of clusters, several runs were conducted varying the number of clusters from two to ten. The final cluster solution was selected by comparing the ratio of between-cluster variance to within-cluster variance divided by the number of clusters. The higher the value of this statistic, the better is the separation of clusters. Based on these determinations and on the nutritional meaningfulness of clusters, we selected the six-cluster solution as the most appropriate number of distinct dietary clusters. Sex-specific cluster analyses were also conducted, yielding very similar results in both men and women and compared with the pooled analysis. Because of the remarkable consistency in our findings by sex, we present data based on the total study population. We interpreted and named the dietary clusters based on their high or low food-group intakes relative to the mean food-group intake across clusters.

For descriptive purposes, sample means, standard deviations and frequencies were calculated for all characteristics of interest by dietary clusters. In preparation for statistical modelling, several transformations of outcome variables were necessary. Because the distribution of $S_{I}$ is skewed right and fifty-eight individuals had an $S_{I}$ value of 0 , we calculated the natural logarithm after adding a constant 1 to assess all values since the log of 0 cannot be taken. With this transformation, the distributions of the resulting residual values approached normality. FI was log-transformed for all analyses. For $\mathrm{S}_{\mathrm{I}}$ and FI, geometric means are presented after back-transformation from the log scale. The standard errors of the back-transformed variables were calculated using the Delta method (Rosner, 2000).

Analysis of covariance was employed to compare mean outcome levels between dietary patterns, corrected for effects of the covariates (Kleinbaum et al. 1988). We first evaluated the impact of potential effect modifiers on mean outcome levels by including dietary cluster by covariate interaction terms in the model and examining the $P$ value for the interaction terms from the type III sum of squares. There was no evidence of interaction by ethnicity, sex or physical activity on any of the four outcomes. In addition, the impact of potential confounders was assessed on an individual basis and then in the full models. Relevant confounders that were retained in the final analysis included age, sex, race and ethnicity, clinic, smoking, family history of diabetes mellitus and usual vigorous physical activity. In a final step, we additionally controlled for total energy intake to isolate the independent role of food-group composition in the dietary patterns.

\section{Results}

Six distinct dietary patterns were identified by cluster analysis as shown in Table 1 . The cluster names were chosen based on the relative ranking of a given food group across each pattern. In this context, it is important to recognise that the absolute food intake averages for some patterns were actually quite similar in comparison with the population mean; however, the patterns differed in the combinations of food groups consumed most frequently. The average food intake by pattern will be described in conjunction with the pattern-specific macronutrient intake shown in Table 2 . The 'fries' pattern demonstrated the highest pattern average intake of the food groups fries (refer to the Appendix for description of items included in each food group), whole milk, regular (i.e. non-diet) soft drinks, pastries and sweets. The 'fries' pattern ranked lowest on intake of low-fat milk products, fish and poultry. This pattern comprised approximately $19 \%$ of the overall population and ranked second in total energy and macronutrient intake.

The 'white bread' pattern had the highest consumption of the food groups white bread, tomatoes, cheese, dried beans, eggs, meats, fats and oils and beer. It ranked highest in terms of average energy intake at $13673 \mathrm{~kJ}$ (3268 kcal) per $d$. The 'low-frequency eater' pattern distinguished itself by the lowest average daily intake of many food groups, which was reflected in the lowest overall energy intake at $5368 \mathrm{~kJ}(1283 \mathrm{kcal})$ per $\mathrm{d}$. This pattern comprised $40 \%$ of the population. Individuals in the 'fruits' pattern were characterised by the highest average intake of fruits and real fruit juices and poultry, in addition to ice cream and meal replacements. This group comprised $27 \%$ of the population.

The 'wine' pattern demonstrated food-group intakes at average levels except for wine and mixed drinks, of which a total of 2.3 servings per $\mathrm{d}$ were consumed. Alcoholic beverages made up almost $14 \%$ of the daily energy intake, which averaged at $7075 \mathrm{~kJ}(1691 \mathrm{kcal})$. The 'wine' pattern comprised only $3.8 \%$ of the population. Additionally, a very small cluster emerged, identified as the 'dark bread' pattern. This cluster was characterised by a very high intake of dark or high-fibre breads and cereals, rice, pasta, a variety of vegetables and also boiled or baked potatoes. This pattern also frequently consumed low-fat milk products, fish, diet soft drinks and tofu. They also exhibited the lowest average intake of meat, eggs and pastry. Energy intake was about average but the percentage energy from fat overall was the lowest of all six dietary patterns. 
Table 1. Food-group intake by dietary pattern in the Insulin Resistance Atherosclerosis Study, 1992-94

\begin{tabular}{|c|c|c|c|c|c|c|c|}
\hline & $\begin{array}{l}\text { Fries, whole milk, } \\
\text { soft drinks, } \\
\text { pastry, sweets }\end{array}$ & $\begin{array}{l}\text { White bread, } \\
\text { tomatoes, } \\
\text { cheese, beans, } \\
\text { meat, beer }\end{array}$ & $\begin{array}{l}\text { Low-frequency } \\
\text { eaters }\end{array}$ & $\begin{array}{l}\text { Fruits, } \\
\text { fruit juices, } \\
\text { poultry }\end{array}$ & $\begin{array}{l}\text { Wine, mixed } \\
\text { drinks }\end{array}$ & $\begin{array}{l}\text { Dark bread, } \\
\text { rice and pasta, } \\
\text { vegetables }\end{array}$ & All \\
\hline Participants: $n$ & 184 & 91 & 395 & 264 & 37 & 9 & 980 \\
\hline & $18 \cdot 8$ & $9 \cdot 3$ & $40 \cdot 3$ & $26 \cdot 9$ & $3 \cdot 8$ & 0.9 & 100 \\
\hline \multicolumn{8}{|l|}{$\begin{array}{l}\text { Food groups } \\
\text { (Servings per d) }\end{array}$} \\
\hline $\begin{array}{l}\text { Fries and fried } \\
\text { potatoes }\end{array}$ & $0.35^{\star}$ & 0.3 & 0.07 & 0.08 & 0.04 & $0.01 \dagger$ & 0.1 \\
\hline $\begin{array}{l}\text { Whole milk } \\
\text { and products }\end{array}$ & $0.25^{*}$ & 0.2 & 0.06 & 0.08 & 0.09 & $0.03+$ & 0.1 \\
\hline Soft drinks & $0.4^{*}$ & 0.3 & 0.2 & 0.1 & $0.05 \dagger$ & 0.1 & 0.2 \\
\hline Pastry & $0.7^{\star}$ & 0.5 & 0.2 & 0.3 & 0.1 & $0.08 \dagger$ & $0 . \overline{3}$ \\
\hline Sweets & $1 \cdot 2^{*}$ & $1 \cdot 1$ & $0.4 \dagger$ & 0.5 & 0.4 & 0.4 & 0.6 \\
\hline $\begin{array}{l}\text { White bread and } \\
\text { low-fibre cereal }\end{array}$ & 1.9 & $3 \cdot 0^{*}$ & 0.8 & $1 \cdot 2$ & $0 \cdot 7 \dagger$ & 0.7 & 1.3 \\
\hline Salty snacks & 0.3 & $0.4^{*}$ & 0.2 & 0.3 & 0.2 & $0.1 \dagger$ & 0.3 \\
\hline Tomatoes & 0.7 & $1.4^{*}$ & $0.4 \dagger$ & 1.0 & 0.7 & 0.9 & 0.7 \\
\hline Cottage cheese & 0.06 & $0.15^{*}$ & 0.04 & 0.1 & 0.07 & $0.02 \dagger$ & $0 \cdot 1$ \\
\hline Cheese & 0.5 & $0.8^{\star}$ & $0.3 \dagger$ & 0.4 & 0.3 & 0.3 & 0.4 \\
\hline Dried beans & 0.3 & $1 \cdot 0^{*}$ & 0.1 & 0.3 & $0 \cdot 1 \dagger$ & 0.3 & 0.3 \\
\hline Eggs & 0.3 & $0.5^{\star}$ & 0.1 & 0.2 & 0.2 & $0.06 \dagger$ & 0.2 \\
\hline Meat & 1.5 & $2 \cdot 3^{*}$ & 0.6 & 0.9 & 0.6 & $0.3 \dagger$ & 1.0 \\
\hline Fats and oils & $1 \cdot 8$ & $2 \cdot 6^{*}$ & 1.2 & $1 \cdot 7$ & $1 \cdot 6$ & $1.0 \dagger$ & 1.6 \\
\hline Coffee and tea & 1.0 & $1 \cdot 1^{\star}$ & $0.6 \dagger$ & 1.0 & 0.8 & 1.0 & 0.8 \\
\hline Beer & 0.3 & $0.9^{*}$ & $0.2 \dagger$ & 0.2 & 0.2 & 0.4 & 0.3 \\
\hline Fruits & $1 \cdot 2$ & 1.8 & $1 \cdot 1 \dagger$ & $2 \cdot 6^{\star}$ & $1 . \overline{3}$ & 1.9 & 1.6 \\
\hline Fruit juices & 0.6 & 0.7 & 0.6 & $1.0^{*}$ & $0.5 \dagger$ & 0.6 & 0.7 \\
\hline Poultry & $0.3 \dagger$ & 0.5 & 0.3 & $0.6^{\star}$ & 0.4 & 0.4 & 0.4 \\
\hline Ice cream & 0.2 & 0.2 & 0.2 & $0.25^{\star}$ & $0.1 \dagger$ & 0.1 & 0.2 \\
\hline Meal replacements & 0 & 0.02 & 0.03 & $0.03^{*}$ & 0 & 0 & 0.02 \\
\hline Wine & $0.03+$ & 0.07 & 0.08 & 0.1 & $1.8^{\star}$ & 0.4 & 0.1 \\
\hline Mixed drinks & 0.08 & 0.3 & 0.2 & 0.2 & $0.5^{\star}$ & $0.07 \dagger$ & 0.2 \\
\hline $\begin{array}{l}\text { Dark bread and } \\
\text { high-fibre cereal }\end{array}$ & $0.6 \dagger$ & 0.7 & $0 . \overline{6}$ & $1 \cdot 2$ & $1 \cdot 1$ & $1 \cdot 7^{\star}$ & 0.8 \\
\hline Rice and pasta & 0.4 & 0.8 & $0.4 \dagger$ & 0.9 & 0.6 & $1 \cdot 0^{*}$ & 0.6 \\
\hline $\begin{array}{l}\text { Cruciferous } \\
\text { vegetables }\end{array}$ & $0.2 \dagger$ & 0.3 & 0.2 & 0.6 & 0.4 & $0 \cdot 8^{*}$ & 0.3 \\
\hline Other vegetables & 1.6 & $2 \cdot 6$ & $1.2 \dagger$ & $2 \cdot 6$ & 1.6 & $3 \cdot 6^{*}$ & 1.8 \\
\hline Potatoes & 0.3 & 0.4 & $0.2 \dagger$ & 0.4 & 0.3 & $0.5^{\star}$ & 0.3 \\
\hline $\begin{array}{l}\text { Low-fat milk } \\
\text { and products }\end{array}$ & $0.1 \dagger$ & 0.2 & 0.2 & 0.4 & 0.4 & $0 \cdot 6^{*}$ & 0.2 \\
\hline Fish & $0.2 \dagger$ & 0.3 & 0.2 & 0.4 & 0.3 & $0.45^{\star}$ & 0.2 \\
\hline $\begin{array}{l}\text { Diet soft drinks } \\
\text { and water }\end{array}$ & $0.9 \dagger$ & 1.5 & 1.2 & 1.6 & 1.2 & $1.6^{*}$ & 1.3 \\
\hline Nuts and seeds & 0.3 & 0.1 & $0.09 t$ & 0.2 & 0.2 & $0.3^{*}$ & 0.2 \\
\hline Tofu & 0 & 0 & 0 & 0 & 0 & $0.3^{*}$ & 0 \\
\hline
\end{tabular}

*High intakes.

†Low intakes (for the food groups tofu and meal replacements no low intakes are marked, as more than one pattern had the same low intake).

Table 3 shows demographic and other behavioural characteristics of the six dietary patterns. Individuals in the 'wine' pattern tended to be older and comprised a higher proportion of men, whereas the 'white bread' and the 'fries' clusters tended to be younger. The vast majority of the 'white bread' and the 'fries' clusters were from the San Antonio and San Luis Valley clinics (80 and 91\%, respectively) and disproportionately of Hispanic ethnicity. The 'low-frequency eater' cluster included a large proportion of African-Americans from the Oakland and Los Angeles clinics (38\%), whereas the 'wine' and 'dark bread' clusters contained disproportionately more non-Hispanic whites from the California clinics. Of note, the "white bread' and the 'fries' clusters had a larger proportion of individuals with less than 12 years of education, who exhibited more sedentary activity behaviours and smoked to a large extent.

Table 4 shows the $S_{\text {I }}$, FI and anthropometric characteristics of the individuals in each pattern, first unadjusted and with subsequent adjustments for age, sex, race and ethnicity, clinic, family history of diabetes, smoking and vigorous physical activity (second set of models) and finally for total energy intake (third set of models). Considering first the unadjusted clinical values, individuals consuming a diet characterised by the 'dark bread' and the 'wine' patterns had the most advantageous insulin resistance and anthropometric profiles in that they had in absolute terms the highest level of $S_{I}$ and the lowest clinical values of FI, BMI and waist circumference. The 'white bread' pattern was associated with the most 
Table 2. Energy and macronutrient intake by dietary pattern in the Insulin Resistance Atherosclerosis Study, 1992-94

(Mean values and standard deviations)

\begin{tabular}{|c|c|c|c|c|c|c|c|c|c|c|c|c|c|c|}
\hline & \multicolumn{2}{|c|}{$\begin{array}{l}\text { Fries, whole } \\
\text { milk, soft } \\
\text { drinks, pas- } \\
\text { try, sweets } \\
(n 184)\end{array}$} & \multicolumn{2}{|c|}{$\begin{array}{l}\text { White bread, } \\
\text { tomatoes, } \\
\text { cheese, } \\
\text { beans, meat, } \\
\text { beer ( } n 91)\end{array}$} & \multicolumn{2}{|c|}{$\begin{array}{l}\text { Low-fre- } \\
\text { quency } \\
\text { eaters } \\
(n 395)\end{array}$} & \multicolumn{2}{|c|}{$\begin{array}{l}\text { Fruits, fruit } \\
\text { juices, poul- } \\
\text { try }(n 264)\end{array}$} & \multicolumn{2}{|c|}{$\begin{array}{l}\text { Wine, mixed } \\
\text { drinks }(n 37)\end{array}$} & \multicolumn{2}{|c|}{$\begin{array}{l}\text { Dark bread, } \\
\text { rice and } \\
\text { pasta, veg- } \\
\text { etables }(n 9)\end{array}$} & \multicolumn{2}{|c|}{ All $(n 980)$} \\
\hline & Mean & SD & Mean & SD & Mean & SD & Mean & SD & Mean & SD & Mean & SD & Mean & SD \\
\hline Total energy $(\mathrm{kJ} / \mathrm{d})$ & \multicolumn{2}{|c|}{9854} & \multicolumn{2}{|c|}{13680} & \multicolumn{2}{|c|}{5371} & \multicolumn{2}{|c|}{8502} & \multicolumn{2}{|c|}{7079} & \multicolumn{2}{|c|}{7267} & \multicolumn{2}{|c|}{7912} \\
\hline Total fat $(\mathrm{g} / \mathrm{d})$ & 101 & $26 \cdot 1$ & 142 & $39 \cdot 3$ & $48 \cdot 6$ & $18 \cdot 9$ & $75 \cdot 9$ & $29 \cdot 3$ & $57 \cdot 1$ & $24 \cdot 3$ & $51 \cdot 2$ & $18 \cdot 3$ & 74.8 & 39.0 \\
\hline Saturated fat $(g / d)$ & 37.6 & $10 \cdot 7$ & $52 \cdot 2$ & $16 \cdot 6$ & $17 \cdot 2$ & $7 \cdot 7$ & $25 \cdot 9$ & 11.9 & $19 \cdot 0$ & 9.7 & 14.7 & 5.9 & $26 \cdot 7$ & $15 \cdot 3$ \\
\hline $\begin{array}{l}\text { Monounsaturated } \\
\text { fat }(g / d)\end{array}$ & $38 \cdot 0$ & $10 \cdot 4$ & 53.5 & $17 \cdot 4$ & $17 \cdot \overline{8}$ & $7 \cdot 2$ & $28 \cdot 1$ & $11 \cdot 2$ & $21 \cdot 3$ & $9 \cdot 2$ & $18 \cdot 9$ & $7 \cdot 0$ & $27 \cdot 8$ & $15 \cdot 0$ \\
\hline $\begin{array}{l}\text { Polyunsaturated } \\
\text { fat }(\mathrm{g} / \mathrm{d})\end{array}$ & $17 \cdot 1$ & $4 \cdot 8$ & $25 \cdot 2$ & $7 \cdot 2$ & $9 \cdot 6$ & $4 \cdot 0$ & $15 \cdot 3$ & $6 \cdot 1$ & 11.4 & $4 \cdot 7$ & $12 \cdot 0$ & 3.9 & $14 \cdot 1$ & $7 \cdot 0$ \\
\hline $\begin{array}{l}\text { Total carbohydrates } \\
\text { (g/d) }\end{array}$ & 267 & $74 \cdot 2$ & 342 & $86 \cdot 9$ & 153 & $53 \cdot 1$ & 244 & $74 \cdot 2$ & 185 & $56 \cdot 1$ & 237 & $92 \cdot 9$ & 219 & 91.4 \\
\hline Total protein (g/d) & $89 \cdot 8$ & 23.5 & 132 & $35 \cdot 0$ & $53 \cdot 1$ & $17 \cdot 8$ & 88.9 & $29 \cdot 6$ & 67.9 & 24.5 & 74.4 & $32 \cdot 4$ & $77 \cdot 7$ & 34.5 \\
\hline Total alcohol $(\mathrm{g} / \mathrm{d})$ & $5 \cdot 2$ & $13 \cdot 2$ & $15 \cdot 1$ & $27 \cdot 2$ & 4.9 & $9 \cdot 7$ & $5 \cdot 1$ & $11 \cdot 2$ & $27 \cdot 1$ & $17 \cdot 8$ & 9.0 & $8 \cdot 8$ & $6 \cdot 8$ & 14.5 \\
\hline Energy from fat (\%) & $38 \cdot 7$ & $5 \cdot 3$ & 39.4 & 5.0 & $33 \cdot 8$ & $7 \cdot 3$ & 33.1 & $6 . \overline{5}$ & $29 \cdot 7$ & $6 \cdot 2$ & $26 \cdot 5$ & 4.6 & 34.8 & 7.1 \\
\hline $\begin{array}{l}\text { Energy from } \\
\text { carbohydrates (\%) }\end{array}$ & $45 \cdot 3$ & 6.5 & $42 \cdot 1$ & $4 \cdot 7$ & $47 \cdot 9$ & $8 \cdot 6$ & $48 \cdot 7$ & $7 \cdot 7$ & 44.4 & $5 \cdot \overline{7}$ & $55 \cdot 1$ & $5 \cdot 8$ & $47 \cdot 0$ & $7 \cdot 9$ \\
\hline $\begin{array}{l}\text { Energy from } \\
\text { protein }(\%)\end{array}$ & $15 \cdot 3$ & 2.5 & $16 \cdot 2$ & $2 \cdot 1$ & $16 \cdot 8$ & $3 \cdot 3$ & $17 \cdot 6$ & $2 \cdot 8$ & $16 \cdot 0$ & $2 \cdot 8$ & $17 \cdot 0$ & $2 \cdot 4$ & $16 \cdot 6$ & $3 \cdot 0$ \\
\hline $\begin{array}{l}\text { Energy from } \\
\text { alcohol (\%) }\end{array}$ & $2 \cdot 2$ & $5 \cdot 2$ & $4 \cdot 8$ & $8 \cdot 4$ & 3.5 & $6 \cdot 2$ & $2 \cdot 3$ & $4 \cdot 3$ & $13 \cdot 9$ & $6 \cdot 4$ & $4 \cdot 8$ & $5 \cdot 2$ & 3.5 & $6 \cdot 2$ \\
\hline
\end{tabular}

disadvantageous characteristics exhibiting marked evidence of insulin resistance and obesity. Differences between dietary patterns for all four outcomes were highly significant with $P$ values $<0.001$.

The second set of models addresses the relationship of dietary patterns to $S_{I}$ and adiposity from an aetiological perspective, taking into account demographic and behavioural characteristics. While all covariates except age included in the second set of models were significantly associated with the outcomes, it was the adjustment for ethnicity and clinic, and to a lesser extent for sex, that explained some of the differences in the insulin resistance and anthropometric parameters between dietary-pattern groups. This adjustment affected the estimated mean outcome levels among the 'wine' and 'dark bread' patterns relatively more. However, statistically significant differences between dietary patterns remained for FI, BMI and waist circumference, while the differences in $\mathrm{S}_{\mathrm{I}}$ lost statistical significance. The third set of models is shown to convey the mediating effect of total energy on the association under study. Additional adjustment for total energy intake attenuated the differences between the "white

Table 3. Demographic and behavioural characteristics by dietary pattern in the Insulin Resistance Atherosclerosis Study, 1992-94 (\%)

\begin{tabular}{|c|c|c|c|c|c|c|c|}
\hline & $\begin{array}{l}\text { Fries, whole milk, } \\
\text { soft drinks, pastry, } \\
\text { sweets ( } n \text { 184) }\end{array}$ & $\begin{array}{l}\text { White bread, } \\
\text { tomatoes, } \\
\text { cheese, beans, } \\
\text { meat, beer ( } n 91)\end{array}$ & $\begin{array}{l}\text { Low frequency } \\
\text { eaters ( } n 395)\end{array}$ & $\begin{array}{c}\text { Fruits, } \\
\text { fruit juices, } \\
\text { poultry }(n 264)\end{array}$ & $\begin{array}{l}\text { Wine, mixed } \\
\text { drinks ( } n 37)\end{array}$ & $\begin{array}{l}\text { Dark bread, } \\
\text { rice and pasta, } \\
\text { vegetables }(n 9)\end{array}$ & $\begin{array}{c}\text { All } \\
(n 980)\end{array}$ \\
\hline Age (years): Mean & 53 & 52 & 55 & 55 & 60 & 56 & 55 \\
\hline SD & $8 \cdot 6$ & $7 \cdot 7$ & $8 \cdot 3$ & $8 \cdot 6$ & $7 \cdot 2$ & $9 \cdot 1$ & $8 \cdot 5$ \\
\hline Sex: Male & $57 \cdot 6$ & $52 \cdot 7$ & $39 \cdot 2$ & $39 \cdot 8$ & $59 \cdot 5$ & $66 \cdot 7$ & $45 \cdot 1$ \\
\hline Female & $42 \cdot 4$ & $47 \cdot 3$ & $60 \cdot 8$ & $60 \cdot 2$ & $40 \cdot 5$ & $33 \cdot 3$ & 54.9 \\
\hline Non-Hispanic white & $22 \cdot 3$ & $20 \cdot 9$ & $16 \cdot 2$ & $21 \cdot 6$ & $8 \cdot 1$ & 0 & $18 \cdot 8$ \\
\hline Hispanic & $58 \cdot 1$ & $70 \cdot 3$ & $21 \cdot 8$ & $28 \cdot 8$ & $5 \cdot 4$ & 0 & $34 \cdot 2$ \\
\hline \multicolumn{8}{|l|}{ Oakland and } \\
\hline \multicolumn{8}{|l|}{ Los Angeles: } \\
\hline Non-Hispanic white & $7 \cdot 6$ & 4.4 & $24 \cdot 0$ & $23 \cdot 5$ & $67 \cdot 6$ & $66 \cdot 7$ & $21 \cdot 0$ \\
\hline African-American & $12 \cdot 0$ & $4 \cdot 4$ & $38 \cdot 0$ & $26 \cdot 1$ & $18 \cdot 9$ & $33 \cdot 3$ & $26 \cdot 0$ \\
\hline Education: $<12$ years & $26 \cdot 1$ & $25 \cdot 3$ & $10 \cdot 6$ & $9 \cdot 5$ & 0 & 0 & $14 \cdot 1$ \\
\hline \multicolumn{8}{|l|}{$\begin{array}{l}\text { Vigorous physical } \\
\text { activity }\end{array}$} \\
\hline Never or rarely & $25 \cdot 5$ & $38 \cdot 4$ & $29 \cdot 6$ & $26 \cdot 5$ & $21 \cdot 6$ & $11 \cdot 1$ & $28 \cdot 4$ \\
\hline 1-4 times/month & $40 \cdot 8$ & $29 \cdot 7$ & 32.9 & $27 \cdot 3$ & $21 \cdot 6$ & $22 \cdot 2$ & $32 \cdot 0$ \\
\hline $2+$ times/week & $33 \cdot 7$ & 31.9 & $37 \cdot 5$ & $46 \cdot 2$ & $56 \cdot 8$ & $66 \cdot 7$ & $39 \cdot 6$ \\
\hline Current smoking & $25 \cdot 5$ & $20 \cdot 9$ & $15 \cdot 4$ & $11 \cdot 0$ & $8 \cdot 1$ & 0 & $16 \cdot 2$ \\
\hline
\end{tabular}


A. D. Liese et al.

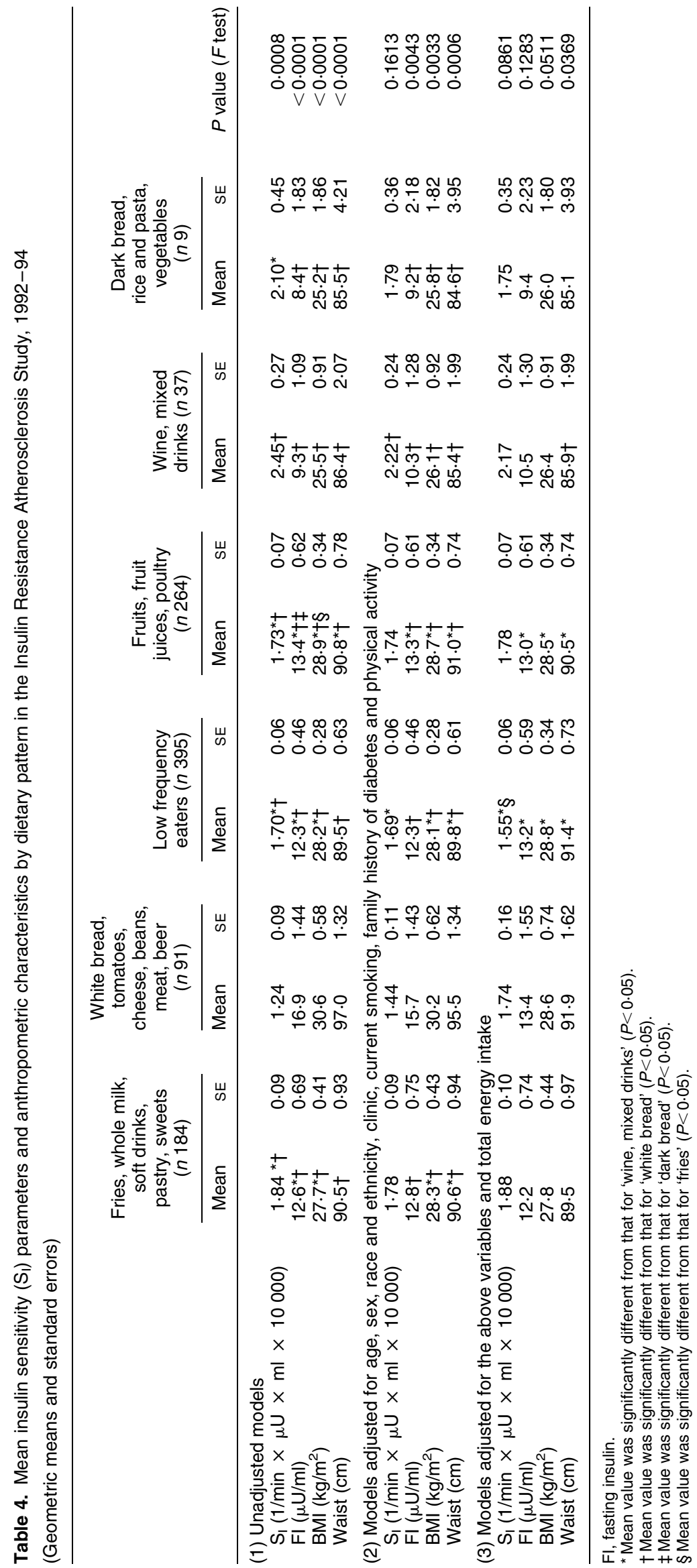


bread' cluster and all of the other diet patterns. Furthermore, it affected the relative ranking of the 'low-frequency eaters', whose profile worsened substantially. Table 5 shows the correlation between the measures of $\mathrm{S}_{\mathrm{I}}$ and adiposity. Because adiposity is a well-known predictor of insulin resistance, we additionally adjusted the final models of $S_{I}$ and FI presented in Table 4 for BMI (data not shown) leading to a further attenuation. This implies that at least part of the cross-sectional association of dietary patterns with $\mathrm{S}_{\mathrm{I}}$ and FI may be accounted for by adiposity.

Fig. 1 visualises the ranking of the six dietary patterns based on their outcome levels adjusting for age, sex, race or ethnicity, clinic, family history of diabetes, smoking and vigorous physical activity. Shown are the absolute differences between $S_{I}$ and anthropometric characteristics and the respective grand means of the IRAS population for each of the dietary patterns. The 'dark bread' and the 'wine' patterns ranked best with regard to FI, BMI and waist circumference, and additionally with regard to $S_{I}$ for the 'wine' cluster, as the adjusted outcome levels in these dietary patterns were markedly better than the population average. The 'low-frequency', 'fries' and the 'fruits' patterns tended to rank third to fifth in terms of health outcome levels, while the 'white bread' pattern ranked last, with outcome levels substantially worse than the population average. Of note, the order of the ranking of the six dietary patterns was highly consistent for BMI, waist circumference and FI.

\section{Discussion}

We identified distinct dietary behaviour patterns based on usual food intake in the IRAS population using cluster analysis. Individuals included in the respective dietary pattern exhibited very similar dietary intake behaviours considering both frequency and type of several food groups simultaneously.

A question raised given the more data-driven nature of these statistical techniques is to what extent the identified patterns are entirely unique to the underlying study

Table 5. Correlations of insulin sensitivity $\left(\mathrm{S}_{1}\right)$, fasting insulin, BMI and waist circumference in the Insulin Resistance Atherosclerosis Study, 1992-94

\begin{tabular}{|c|c|c|c|c|c|c|}
\hline & \multicolumn{2}{|c|}{$\log \left(S_{I}+1\right)$} & \multicolumn{2}{|c|}{ Log insulin } & \multicolumn{2}{|c|}{ BMI } \\
\hline & Correlation & $P$ & Correlation & $P$ & Correlation & $P$ \\
\hline $\log \left(S_{I}+1\right)$ & \multicolumn{2}{|c|}{ - } & \multicolumn{2}{|c|}{ - } & \multicolumn{2}{|c|}{ _- } \\
\hline Log insulin & -0.621 & $<0.0001$ & \multicolumn{2}{|c|}{-} & \multicolumn{2}{|c|}{-} \\
\hline BMI & -0.501 & $<0.0001$ & 0.492 & $<0.0001$ & - & \\
\hline Waist & -0.538 & $<0.0001$ & 0.497 & $<0.0001$ & 0.803 & $<0.0001$ \\
\hline
\end{tabular}
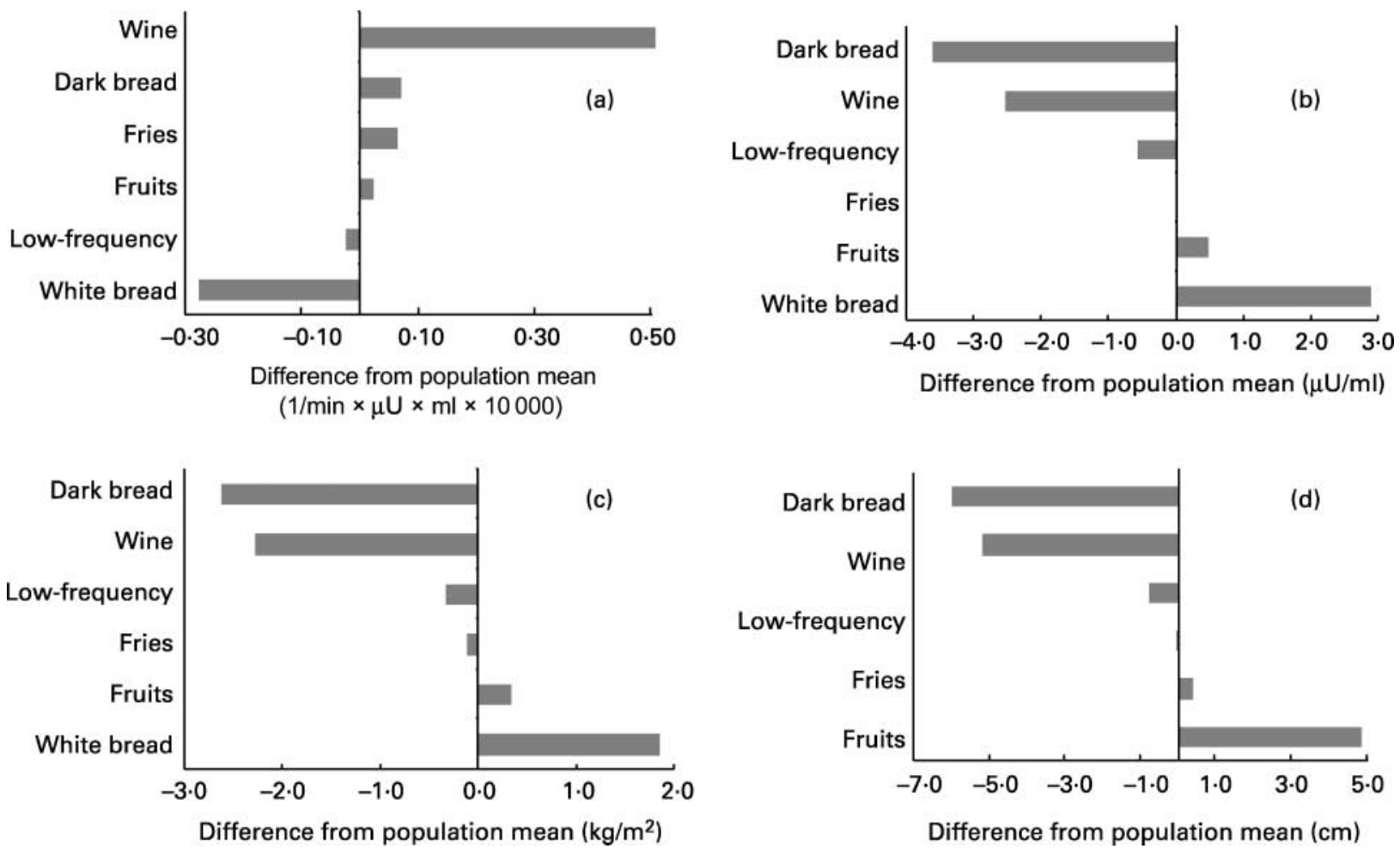

Fig. 1. Differences in insulin sensitivity (a), fasting insulin (b), BMI (c) and waist circumference (d) between dietary-pattern groups and the total population averages, adjusted for age, sex, race and ethnicity, clinic, family history of diabetes, smoking and vigorous physical activity. 
population, and thus of limited value for inferences. The larger dietary patterns observed in the IRAS population, the 'fries', 'white bread', 'fruits', 'low-frequency' and 'wine' patterns, are consistent with findings from several other US populations. Among white American women participating in the Framingham Offspring-Spouse study (Millen et al. 2001), cluster analyses identified a large group of 'light eaters' that mirrors our 'low-frequency eaters', a group of 'heart healthy' whose high intake of fruit, vegetables, low-fat milk products and diet beverages mirrors our 'fruits' group, and a 'wine and moderate eating group' that resembled our 'wine and mixed drink' group. A recent publication on the Baltimore Longitudinal Study (Newby et al. 2003) including white Americans similarly identified a 'white bread', 'alcohol', 'sweets', 'meat-and-potatoes' and a 'healthy' pattern. Additionally, two dominant dietary patterns identified by factor analysis, a 'prudent' pattern also termed 'vegetable-fruit' pattern and a 'Western' or 'red meat-starch' pattern, provide additional support for the consistency of these dietary patterns across populations (Hu et al. 1999; Tseng \& DeVellis, 2001).

While it is generally recognised that there are ethnic and cultural influences on food preferences (Borrud et al. 1989; Coates \& Monteilh, 1997), it is less clear to what extent these overlap or are distinct from regional influences. To date, very little research on dietary patterns and health outcomes has incorporated study populations comprising multiple ethnic groups (Akin et al. 1986; Maskarinec et al. 2000) or non-white populations (Tseng et al. 2000), and even less is known about regional differences in dietary patterns. Given that the IRAS was a multi-centre study and included African-American, Hispanic and non-Hispanic white participants, the food-frequency questionnaire was specifically designed to include regional and ethnic food choices, such as red and green chilli, flour and corn tortillas and ham hocks (Mayer-Davis et al. 1999). Our dietary-pattern results provide specific evidence for the existence of these regional differences in dietary patterns, as $91 \%$ of the 'white bread' pattern and $80 \%$ of the 'fries' pattern constituents came from the San Antonio, TX and the San Luis Valley, CO centres, whereas $87 \%$ of the 'wine' pattern subjects arose from the two California centres. In part due to the IRAS design, these regional differences overlapped with ethnic identity. Among the Mexican-American population surveyed in NHANES III, Tseng et al. (2000) identified a 'high-energy' food pattern comprising white bread, pastries, salty snacks, processed meats and flour tortillas distinct from a 'traditional food' pattern that included beans, corn tortillas, chilli peppers and whole milk. Elements of both these patterns seemed to be represented in our 'white bread' and our 'fries' patterns. A possible explanation is again a more regional differentiation that we were able to ascertain, as the Hispanic population of the 'fries' pattern came predominantly from the San Luis Valley centre, while the Hispanic population of the 'white bread' pattern came primarily from the San Antonio centre. However, it is also important to recognise that each of the three ethnic groups was represented to some extent in each of the larger dietary patterns.
The dietary patterns identified in our population corresponded to marked differences in behaviourally modifiable metabolic and anthropometric outcomes, such as $\mathrm{S}_{\mathrm{I}}$, FI, BMI and waist circumference, lending face validity to the patterns. We consistently observed that the "white bread' pattern was associated with the worst levels of $S_{I}$ and adiposity, while the 'dark bread' and the 'wine' patterns ranked best. Only very few studies to date have evaluated dietary patterns in relation to components of the metabolic syndrome. A higher prevalence of hyperinsulinaemia was reported among women whose dietary pattern was dominated by refined grains (Wirfält et al. 2001). Also consistent with the present findings, Wirfält et al. (2001) demonstrated that men in the 'fibre bread' group were least likely to be centrally obese. In the IRAS, the 'dark bread' pattern (i.e. high-fibre breads and cereals), which also had the highest fibre intake relative to energy intake, was associated with a much lower BMI and waist circumference in addition to lower insulin levels. Others have reported that higher scores on the 'Western' diet scale identified through factor analysis were associated with increased insulin levels (Fung et al. 2001) and predictive of diabetes and CHD ( $\mathrm{Hu}$ et al. 2000; $\mathrm{Hu} \&$ Willett, 2001; van Dam et al. 2003). More recently, Newby et al. (2003) studied the impact of dietary patterns on changes in BMI and waist circumference. Similar to the present data, their 'white bread' and 'meat-and-potato' clusters showed markedly higher levels of adiposity than their 'healthy' group at baseline. Furthermore, they also experienced the highest mean annual increase in BMI and waist circumference.

Another group with a particularly unfavourable metabolic and anthropometric profile comprised the 'low-frequency eaters'. Of this group, $30 \%$ reported being on any type of diet, the vast majority thereof on a low-fat diet, which was reflected in the lowest average fat intake and on average $5368 \mathrm{~kJ}$ (1283 kcal) per d. Compared with the other dietary patterns, the relatively disadvantageous levels of $\mathrm{S}_{\mathrm{I}}$ and adiposity among the 'low-frequency eaters' became even worse after taking into account their low energy intake. Even though women comprised $60 \%$ of this large cluster, it is unlikely that lower food intake in women is responsible because food intake was ascertained using sex-specific portion sizes. Furthermore, the results of our sex-specific cluster analysis identified a cluster of 'low-frequency eaters' in both sex groups. Given the cross-sectional nature of our data, we can only speculate here, but it is conceivable that this group is actively trying to change their dietary behaviour due to increased health awareness. Additionally, this group may also include individuals who systematically under-report dietary intake, which is more commonly observed among individuals who have changed their diet (Wirfält et al. 2000).

Two distinct types of alcoholic beverage intake associated with very different anthropometric profiles emerged from our data. The 'wine' group consumed almost two servings per $d$ plus half a serving of liquor and exhibited low adiposity levels. In contrast, the 'white bread' group exhibited the highest intake of beer at close to one serving per $\mathrm{d}$ and showed marked evidence of central adiposity in addition to overall obesity. Central adiposity associated 
with an increased intake of non-wine alcohol has been previously described in the US-based Atherosclerosis Risk in Communities Study (Duncan et al. 1995). However, subsequent investigations (Dallongeville et al. 1998; Vadstrup et al. 2003) conducted in European populations have been inconclusive. Duncan et al. (1995) raise the question whether the differences in central adiposity observed between wine and beer drinkers are a function of the alcoholic beverage or of other correlated characteristics of drinkers. The IRAS results indicate that the preferred choice of alcoholic beverage is highly associated with other health-related characteristics of the dietary patterns; this needs to be considered in future studies. Disentangling these influences will be challenging.

One of the most complicated issues in nutritional epidemiology is the evaluation and interpretation of the role of total energy intake. Because we were specifically interested in identifying dietary patterns that reflected the totality of food intake, including the frequency, type and combinations of foods, cluster analysis was performed on the dietary intake data at the level of servings per $d$ of each of the thirty-three food groups (Pryer et al. 2001) after standardising the raw dietary intake data to the standard normal. Thus, all food groups had an equal influence on the clustering procedure. Our dietary patterns thus differed substantially in the frequency and type of specific individual foods and their combinations and, thus, also in overall energy intake, which we conceptualise as a mediator.

To better understand the specific mediating influence of total energy intake on the observed differences in $\mathrm{S}_{\mathrm{I}}$, FI and adiposity between the dietary patterns, the present results are presented with and without adjustment for total energy. When we evaluated the total impact of the dietary pattern (second set of models, non-energy-adjusted), expressing the quality of the foods and their combinations in addition to their contribution to total energy intake, the differences between dietary patterns were quite pronounced though the issue of multiple comparisons needs to be kept in mind. Additional adjustment for total energy intake revealed that some, but not all, outcome differences in our population were mediated in part by the total energy component of the dietary patterns. Previous studies have also demonstrated effects of dietary patterns that were independent of energy intake (Fung et al. 2001; Wirfält et al. 2001).

In conclusion, the cluster analytic approach allowed us to characterise in clinically meaningful terms the groups of individuals belonging to unique dietary behaviour patterns with regard to their levels of $S_{I}$ and adiposity and correlated characteristics. The food and nutrient intake differences observed between the dietary patterns were strongly mirrored in the degree of $S_{I}$ and the level of adiposity implicitly validating the empirically derived dietary patterns. Jacobs \& Steffen (2003) have recently pointed out the complementary nature of research on dietary patterns, foods and individual nutrients or food components. The present study on dietary patterns and their associations with $S_{I}$ and adiposity builds on previous findings in the IRAS population, for example, the relationship of whole-grain-containing foods with $\mathrm{S}_{\mathrm{I}}$ (Liese et al.
2003). While the theme of whole $v$. refined grains emerged from the dietary-pattern analysis, it is important to note that the fuller utilisation of the dietary data in the pattern approach unveiled several underlying and correlated dietary behaviour patterns. More work is needed to develop an integrated approach toward analysing patterns, foods and nutrients and their relationship to health outcomes in a manner that better captures the hierarchical nature of dietary data.

\section{Acknowledgements}

The present study was supported by NIH/NHLBI grants UO1 HL/17887, UO1 HL/17889, UO1 HL/17890, UO1 HL/17892, UO1 HL/17902 and DK29867 and by an American Diabetes Association Clinical Research Award to A. D. L. We would also like to acknowledge Genean J. Hainsworth for technical assistance and Fang Fang for statistical assistance.

\section{References}

Akin JS, Guilkey DK, Popkin BM \& Fanelli MT (1986) Cluster analysis of food consumption patterns of older Americans. $J$ Am Diet Assoc 86, 616-624.

Bergman RN, Finegood DT \& Ader M (1985) Assessment of insulin sensitivity in vivo. Endocr Rev 6, 45-86.

Borrud LG, McPherson RS, Nichaman MZ, Pillow PC \& Newell GR (1989) Development of a food frequency instrument: ethnic differences in food sources. Nutr Cancer 12, 201-211.

Coates RJ \& Monteilh CP (1997) Assessments of food-frequency questionnaires in minority populations. Am J Clin Nutr 65, 1108S-1115S.

Dallongeville J, Marecaux N, Ducimetiere P, Ferrieres J, Arveiler D, Bingham A, Ruidavets JB, Simon C \& Amouyel P (1998) Influence of alcohol consumption and various beverages on waist girth and waist-to-hip ratio in a sample of French men and women. Int J Obes Relat Metab Disord 22, 1178-1183.

Duncan BB, Chambless LE, Schmidt MI, Folsom AR, Szklo M, Crouse JR III \& Carpenter MA (1995) Association of the waist-to-hip ratio is different with wine than with beer or hard liquor consumption. Atherosclerosis Risk in Communities Study Investigators. Am J Epidemiol 142, 1034-1038.

Fung TT, Rimm EB, Spiegelman D, Rifai N, Tofler GH, Willett WC \& Hu FB (2001) Association between dietary patterns and plasma biomarkers of obesity and cardiovascular disease risk. Am J Clin Nutr 73, 61-67.

Herbert V, Lau KS, Gottlieb CW \& Bleicher SJ (1965) Coated charcoal immunoassay of insulin. J Clin Endocrinol Metab 25, 1375-1384.

Hu FB, Rimm E, Smith-Warner SA, Feskanich D, Stampfer MJ, Ascherio A, Sampson L \& Willett WC (1999) Reproducibility and validity of dietary patterns assessed with a food-frequency questionnaire. Am J Clin Nutr 69, 243-249.

Hu FB, Rimm EB, Stampfer MJ, Ascherio A, Spiegelman D \& Willett WC (2000) Prospective study of major dietary patterns and risk of coronary heart disease in men. Am J Clin Nutr 72, 912-921.

Hu FB \& Willett WC (2001) Diet and coronary heart disease: findings from the Nurses' Health Study and Health Professionals' Follow-up Study. J Nutr Health Aging 5, 132-138.

Jacobs DR Jr \& Steffen LM (2003) Nutrients, foods, and dietary patterns as exposures in research: a framework for food synergy. Am J Clin Nutr 78, 508S-513S. 
Kleinbaum D, Kupper LL \& Muller KE (1988) Applied Regression Analysis and Other Multivariable Methods. Boston, MA: PWS-KENT Publishing Company.

Liese AD, Roach AK, Sparks KC, Marquart L, D' Agostino RB Jr \& Mayer-Davis EJ (2003) Whole-grain intake and insulin sensitivity: the Insulin Resistance Atherosclerosis Study. Am J Clin Nutr 78, 965-971.

Manson JE, Nathan DM, Krolewski AS, Stampfer MJ, Willett WC \& Hennekens CH (1992) A prospective study of exercise and incidence of diabetes among US male physicians. JAMA 268, 63-67.

Maskarinec G, Novotny R \& Tasaki K (2000) Dietary patterns are associated with body mass index in multiethnic women. $J$ Nutr 130, 3068-3072.

Mayer-Davis EJ, D'Agostino R Jr, Karter AJ, Haffner SM, Rewers MJ, Saad M \& Bergman RN (1998) Intensity and amount of physical activity in relation to insulin sensitivity: the Insulin Resistance Atherosclerosis Study. JAMA 279, 669-674.

Mayer-Davis EJ, Vitolins MZ, Carmichael SL, Hemphill S, Tsaroucha G, Rushing J \& Levin S (1999) Validity and reproducibility of a food frequency interview in a Multi-Cultural Epidemiology Study. Ann Epidemiol 9, 314-324.

Millen BE, Quatromoni PA, Copenhafer DL, Demissie S, O'Horo CE \& D'Agostino RB (2001) Validation of a dietary pattern approach for evaluating nutritional risk: the Framingham Nutrition Studies. J Am Diet Assoc 101, 187-194.

Morrison DF (1990) Multivariate Statistical Methods, 3rd ed. New York: McGraw-Hill.

Newby PK, Muller D, Hallfrisch J, Qiao N, Andres R \& Tucker KL (2003) Dietary patterns and changes in body mass index and waist circumference in adults. Am J Clin Nutr 77, $1417-1425$.

Pacini G \& Bergman RN (1986) MINMOD: a computer program to calculate insulin sensitivity and pancreatic responsivity from the frequently sampled intravenous glucose tolerance test. Comput Methods Programs Biomed 23, 113-122.

Pryer JA, Nichols R, Elliot P, Thakrar B, Brunner E \& Marmot M (2001) Dietary patterns among a national random sample of British adults. J Epidemiol Community Health 55, 29-37.

Romesburg HC (1984) Cluster Analysis for Researchers. Belmont, CA: Lifetime Learning Publications.

Rosner B (2000) Fundamentals of Biostatistics, 5th ed. Pacific Grove, CA: Duxbury Press.
Saad MF, Anderson RL, Laws A, Watanabe RM, Kades WW, Chen YD, Sands RE, Pei D, Savage PJ \& Bergman RN (1994) A comparison between the minimal model and the glucose clamp in the assessment of insulin sensitivity across the spectrum of glucose tolerance. Insulin Resistance Atherosclerosis Study. Diabetes 43, 1114-1121.

Togo P, Osler M, Sorensen TI \& Heitmann BL (2001) Food intake patterns and body mass index in observational studies. Int J Obes Relat Metab Disord 25, 1741-1751.

Tseng M \& DeVellis RF (2001) Fundamental dietary patterns and their correlates among US whites. J Am Diet Assoc 101, 929-932.

Tseng M, DeVellis RF, Maurer KR, Khare M, Kohlmeier L, Everhart JE \& Sandler RS (2000) Food intake patterns and gallbladder disease in Mexican Americans. Public Health Nutr 3, 233-243.

Vadstrup ES, Petersen L, Sorensen TI \& Gronbaek M (2003) Waist circumference in relation to history of amount and type of alcohol: results from the Copenhagen City Heart Study. Int J Obes Relat Metab Disord 27, 238-246.

van Dam RM, Grievink L, Ocke MC \& Feskens EJ (2003) Patterns of food consumption and risk factors for cardiovascular disease in the general Dutch population. Am J Clin Nutr 77, 1156-1163.

van Dam RM, Rimm EB, Willett WC, Stampfer MJ \& Hu FB (2002) Dietary patterns and risk for type 2 diabetes mellitus in U. S. men. Ann Intern Med 136, 201-209.

Wagenknecht LE, Mayer EJ, Rewers M, et al. (1995) The Insulin Resistance Atherosclerosis Study (IRAS) objectives, design, and recruitment results. Ann Epidemiol 5, 464-472.

Wirfält E, Mattisson I, Gullberg B \& Berglund G (2000) Food patterns defined by cluster analysis and their utility as dietary exposure variables: a report from the Malmo Diet and Cancer Study. Public Health Nutr 3, 159-173.

Wirfält E, Hedblad B, Gullberg B, Mattisson I, Andren C, Rosander U, Janzon L \& Berglund G (2001) Food patterns and components of the metabolic syndrome in men and women: a cross-sectional study within the Malmo Diet and Cancer cohort. Am J Epidemiol 154, 1150-1159.

World Health Organization (1985) Diabetes Mellitus. Technical Report Series no. 727. Geneva: WHO.

Yang YJ, Youn JH \& Bergman RN (1987) Modified protocols improve insulin sensitivity estimation using the minimal model. Am J Physiol 253, E595-E602. 
Appendix 1. Food groups and corresponding food items in the Insulin Resistance Atherosclerosis Study, 1992-94*

\begin{tabular}{|c|c|}
\hline Food group & Food items included in food group \\
\hline $\begin{array}{l}\text { Dark bread and } \\
\text { high-fibre cereal }\end{array}$ & Dark bread, high-fibre cereal, cooked cereal (0.5), bran \\
\hline $\begin{array}{l}\text { White bread and } \\
\text { low-fibre cereal }\end{array}$ & $\begin{array}{l}\text { White bread, biscuits, flour and corn tortilla, corn bread, fortified cereal, cold cereal, } \\
\text { sweetened cereal, cooked cereal }(0 \cdot 5) \text {, pizza, burritos, enchiladas, tacos }\end{array}$ \\
\hline Salty snacks & Crackers, crisps (potato chips), corn chips, tortilla chips, pretzels, popcorn \\
\hline Rice and pasta & $\begin{array}{l}\text { Rice (plain); pasta, noodles, fideo, couscous (without cheese or tomato sauce); } \\
\text { spaghetti, lasagne, other pasta or mixed dishes with tomatoes or tomato sauce; } \\
\text { macaroni and cheese; Asian food; sushi }(0.5)\end{array}$ \\
\hline Tomatoes & $\begin{array}{l}\text { Tomatoes, tomato juice; salsa picante, taco sauce }(0.5) \text {; spaghetti, lasagne, } \\
\text { other pasta or mixed dishes with tomatoes or tomato sauce; pizza }(0.5) \text {; } \\
\text { enchiladas, tamales, tacos, tostades, chalupas, other Mexican dishes with corn } \\
\text { tortillas }(0.5) \text {; vegetable and tomato soup }(0.5)\end{array}$ \\
\hline Cruciferous vegetables & Broccoli; cauliflower or Brussels sprouts; coleslaw, cabbage, sauerkraut \\
\hline Other vegetables & $\begin{array}{l}\text { String beans, green beans; peas; corn; winter squash, baked squash; mustard greens, } \\
\text { turnip greens, collards; carrots or mixed vegetables; spinach (cooked or raw); } \\
\text { any other vegetable, including cooked onions, summer squash, asparagus, sweet peppers, } \\
\text { bok choy, okra, etc; beef or chicken stew with carrots or other vegetables }(0.5) \text {; } \\
\text { red and green chilli con carne; Asian food; vegetable or tomato soup }(0.5) \text {; pumpkin pie, } \\
\text { sweet potato pie, empanadas with pumpkin }(0.5) \text {; chilli with beans }(0.5) \text {; green chillis }(0.5) \text {; } \\
\text { pickles (0.5); jicama }\end{array}$ \\
\hline Potatoes & Sweet potatoes, yams; other potatoes such as boiled, baked, mashed, potato salad \\
\hline Fries & French fries, fried potatoes \\
\hline Fruits & $\begin{array}{l}\text { Apples, apple sauce, pears; bananas; peaches, apricots, nectarines (canned, frozen, } \\
\text { or dried, whole year) }(0 \cdot 85) ; \text { peaches, apricots, nectarines (fresh, when in season) }(0 \cdot 15) \text {; } \\
\text { cantaloupe (when in season) }(0 \cdot 15) \text {; watermelon (when in season) }(0 \cdot 15) \text {; strawberries } \\
\text { (fresh, when in season) }(0 \cdot 15) ; \text { oranges; grapefruit; dried fruits, including raisins, prunes, } \\
\text { figs; any other fruit (other melon, grapes, berries, fruit cocktail, persimmon, etc); } \\
\text { avocado, guacamole; cranberry sauce; lemon, lime }\end{array}$ \\
\hline Fruit juices & $\begin{array}{l}\text { Orange juice or grapefruit juice; other fruit juice with vitamin } \mathrm{C} \text {, including fortified fruit drinks, } \\
\text { hi-c, kool-aid, cranberry juice, tang; any other fruit juice (apple juice, grape juice) }\end{array}$ \\
\hline Cottage cheese & Cottage cheese, ricotta cheese \\
\hline Cheese & $\begin{array}{l}\text { Pizza; mixed dish with cheese (including macaroni and cheese, chilli rellenos, cheese } \\
\text { quesadillas quiche); enchiladas, tamales, tacos, tostades, chalupas, other Mexican dishes } \\
\text { with corn tortillas, including nachos with chilli and cheese }(0.5) \text {; cream soups }(0.5) \text {; } \\
\text { cheese (Cheddar, American, cream cheese, Parmesan, Velveeta, other cheeses or } \\
\text { cheese spreads; including on sandwiches or as snacks) }\end{array}$ \\
\hline $\begin{array}{l}\text { Low-fat milk } \\
\text { and products }\end{array}$ & $\begin{array}{l}\text { Low-fat plain or flavoured yoghurt ( } 2 \% \text { or non-fat); } 2 \% \text { milk and beverages with } 2 \% \text { milk; } \\
\text { skimmed milk, } 1 \% \text { or buttermilk, and beverages made with these }\end{array}$ \\
\hline $\begin{array}{l}\text { Whole milk } \\
\text { and products }\end{array}$ & $\begin{array}{l}\text { Flavoured yoghurt (regular, from whole milk); whole milk and beverages with whole milk; } \\
\text { milk in coffee or tea }(0.5) \text {; cream (real) or half-and-half in coffee or tea }(0.5) \text {; milk shake; } \\
\text { other dairy products }\end{array}$ \\
\hline Fish & $\begin{array}{l}\text { Fried fish or fish sandwich; tuna fish, salmon, sardines (including tuna salad, tuna casserole); } \\
\text { shellfish (shrimp, lobster, crab, oysters, mussels, etc); other grilled (broiled) or baked fish, } \\
\text { including trout, sole, halibut, etc; sushi }\end{array}$ \\
\hline Dried beans & $\begin{array}{l}\text { Refried beans (as side dish, not including those in burritos, etc); other beans such as pintos, } \\
\text { black beans, chick peas (garbanzos), baked beans, or lentils; burritos, including breakfast } \\
\text { burritos, soft taco with flour tortillas (0.5); chilli with beans }\end{array}$ \\
\hline Eggs & Eggs, omelettes, frittata \\
\hline Meat & $\begin{array}{l}\text { Hamburgers, cheeseburgers, meat loaf, picadillo, carne guisada (asada); } \\
\text { beef (steaks, roasts, etc, including on sandwiches); beef stew or pot pie with } \\
\text { carrots or other vegetables; pork, including chops, roasts, or ribs; ham, ham hocks } \\
\text { (including ham on sandwiches); game, including venison, rabbit; liver, including } \\
\text { chicken livers; burritos, including breakfast burritos, soft taco with flour tortillas; } \\
\text { green chilli con carne; Asian food; liverwurst; hot dogs (including pork, beef, turkey); } \\
\text { bologna, salami, spam, other lunch meats (excluding ham); bacon; sausage, chorizo; } \\
\text { veal, lamb; Italian sausage; pâté }\end{array}$ \\
\hline Poultry & $\begin{array}{l}\text { Chicken, turkey, or wild fowl (roasted, grilled (broiled) or minced (ground), } \\
\text { including on sandwiches); chicken or turkey stew or pot pie with carrots or } \\
\text { other vegetables; fried chicken; duck }\end{array}$ \\
\hline
\end{tabular}

Soft drinks

Diet soft drinks and water

Ice cream
White bread, biscuits, flour and corn tortilla, corn bread, fortified cereal, cold cereal omatoes, tomato juice; salsa picante, taco sauce (0.5); spaghetti, lasagne, other pasta or mixed dishes with tomatoes or tomato sauce; pizza (0.5); tortillas $(0.5)$; vegetable and tomato soup (0.5)

roccoli; cauliflower or Brussels sprouts; coleslaw, cabbage, sauerkraut turnip greens, collards; carrots or mixed vegetables; spinach (cooked or raw); any other vegetable, including cooked onions, summer squash, asparagus, sweet peppers, choy, okra, etc; beef or chicken stew with carrots or other vegetables (0.5); , pickles (0.5); jicama

Sweet potatoes, yams; other potatoes such as boiled, baked, mashed, potato salad French fries, fried potatoes

Apples, apple sauce, pears; bananas; peaches, apricots, nectarines (canned, frozen, dried, whole year) (0.85); peaches, apricots, nectarines (fresh, when in season) (0.15); (fresh, when in season) (0.15); oranges; grapefruit; dried fruits, including raisins, prunes, figs; any other fruit (other melon, grapes, berries, fruit cocktail, persimmon, etc) avocado, guacamole; cranberry sauce; lemon, lime Cottage cheese, ricotta cheese

Pzza; mixed dish with cheese (including macaroni and cheese, chilli rellenos, cheese with corn tortillas, including nachos with chilli and cheese (0.5); cream soups (0.5); cheese (Cheddar, American, cream cheese, Parmesan, Velveeta, other cheeses or cheese spreads; including on sandwiches or as snacks)

milk in other dairy products

as pintos

Eggs, omelettes, frittata carrots or other vegetables; pork, including chops, roasts, or ribs; ham, ham hocks ( bologna, salami, spam, other lunch meats (excluding ham); bacon; sausage, chorizo;

Chicken, turkey, or wild fowl (roasted, grilled (broiled) or minced (ground), other vegetables; fried chicken; duck

Regular soft drinks (including colas, 7-up, etc); lemonade, sweetened mineral water Diet soft drinks; glasses of plain water or unflavoured mineral water

Ice cream; frozen yoghurt, ice milk; mellorine 
Appendix 1. Continued

\begin{tabular}{|c|c|}
\hline Food group & Food items included in food group \\
\hline Pastry & $\begin{array}{l}\text { Doughnuts, cookies, cakes, pastry, brownies, sopapillas, pan dulce; pumpkin pie, } \\
\text { sweet potato pie, empanadas with pumpkin; other pies }\end{array}$ \\
\hline Sweets & $\begin{array}{l}\text { Sugar, molasses, or honey added to cereal; chocolate including Hershey's Kisses, } \\
\text { M\&M's, chocolate candy bars; other candy, jelly, honey, brown sugar, jams, } \\
\text { or molasses, including on bread or other foods; sugar in coffee or tea, or honey in tea } \\
\text { (not including artificial sweeteners); pudding; other sweets; Ketchup }(0 \cdot 25) \text {; } \\
\text { sherbet or jelly (jello) }\end{array}$ \\
\hline Fats and oils & $\begin{array}{l}\text { Diet salad dressing, diet mayonnaise (including on sandwiches) (0.5); } \\
\text { salad dressing, mayonnaise, tartar sauce (including on sandwiches); butter, margarine, } \\
\text { or other fat on vegetables, potatoes, rice, etc; tuna fish, salmon, sardines } \\
\text { (including tuna salad, tuna casserole) (0.25); margarine on bread or roll; butter on } \\
\text { bread or roll; gravies made with meat drippings, or white sauce; non-dairy creamer } \\
\text { in coffee or tea (0.5); fat or oil in cooking; sour cream, other dips; olives }\end{array}$ \\
\hline Nuts and seeds & Nuts and seeds, including peanuts, peanut butter, pine nuts, sunflower seeds \\
\hline Coffee and tea & $\begin{array}{l}\text { Coffee, regular (not decaffeinated); decaffeinated coffee; tea (hot or iced) } \\
\text { (including black tea and herbal tea) }\end{array}$ \\
\hline Tofu & Tofu or tempeh \\
\hline Meal replacements & Instant breakfast \\
\hline Beer & Beer \\
\hline Mixed drinks & Mixed drinks; mixers \\
\hline Wine & Red wine, white wine \\
\hline
\end{tabular}

*Values in parentheses are weighting factors applied to the number of servings per $d$ for items contributing to more than one food group or for items contributing different proportions to one food group according to their actual consumption. 